\title{
Client satisfaction to antiretroviral treatment services and associated factors among clients attending ART clinics in Hossana Town, Southern Ethiopia
}

\author{
Feleke Doyore*, and Beminet Moges \\ Faculty of Medicine and Health Science, Department of Public Health, Wachemo University, PO Box: 667, Hossana, Ethiopia
}

\begin{abstract}
Background: Provision of services for Human Immunodeficiency Virus (HIV) infection as devastating diseases is a concern of Ethiopian government by advancing a comprehensive HIV care and treatment program that includes access to anti-retroviral therapy. and then evaluating client satisfaction is a crucial part to improve efficiency of services, eliciting the opinion of users about the available services and identifying factors associated with satisfaction which is the aim this study.

Methods: Facility based cross sectional study design was conducted from January- February, 2015. Consecutive sampling technique was applied to select individual member of client. Data was analyzed by using SPSS version 16.0. Multiple Linear regressions were used to identify independent predictors. Qualitative data was collected using in-depth interview with clients and health providers and used for concurrent triangulation with quantitative.

Results: Client satisfaction to antiretroviral treatment ART services was $70.10 \%(211 / 301)$. As independent predictors, perceived availability of the services $[\beta$ (95\% $\mathrm{CI})=1.79(1.07-3.01)$, perceived patient provider interaction $[\beta(95 \% \mathrm{CI})=1.76(1.07-2.88)$, perceived privacy during examination $[\beta(95 \% \mathrm{CI})=1.16(1.03-1.31)]$, perceived confidentiality of medical record $[\beta(95 \% \mathrm{CI})=1.26(0.67-0.98)$, educational status (primary school completed) $[\beta(95 \% \mathrm{CI})=2.41(3.97$ to 9.74$)]$, and clients who disclosed their HIV status to their parents $[\beta(95 \% \mathrm{CI})=4.33(2.39$ to 8.18$)]$ were associated with client satisfaction to ART. In total, $73.17 \%$ of the variance in the quality of services in terms of client satisfaction could be explained by Donebidean model.

Conclusion: Despite higher numbers of clients were satisfied in the services provided, significantly intolerable numbers were not satisfied. Therefore, due attention should be given to fill the gap of perception of the clients through ART mentorship by inaugurating with IEC/BCC in the context of their educational level and in their living situation.
\end{abstract}

\section{Introduction}

Human immunodeficiency virus (HIV) infection, a worldwide phenomenon, is a serious public health challenge. Ethiopia is one of the many countries in Sub-Sahara Africa that is hardly hit by the HIV/AIDS epidemic. For this, the Government of Ethiopia has been conducting a comprehensive HIV care and treatment program that includes access to anti-retroviral therapy. Client satisfaction is a vital component to improve efficiency of services, eliciting the opinion of users about the available services and identifying factors associated with dissatisfaction is very critical [1-3].

According to reports from the joint united nations program on HIV/AIDS (UNAIDS) the global burden of HIV/AIDS is one of the most destructive epidemics the world has ever witnessed. Nearly 23 million of the 33.2 million lived in sub-Saharan Africa. Global AIDS death in adults and children were estimated at 2.1million of whom 1.6 million was again from sub Saharan Africa [4].

Much effort has been put into the scaling up of access to ART [5]. The efficacy of ART depends largely on compliance to treatment regimens. Poor patient satisfaction is associated with poor virological and immunological response. It is also responsible for the development of resistant strains [6]. Very high levels (> 95\%) of adherence are necessary for sustained clinical success [7]. Numerous reports have documented that the key to the success of the new ART is the ability and willingness of HIV-positive individuals to adhere to complex ARV regimens, and at least 95\% adherence (missing no more than three doses per month) is required for ARV regimens to be fully effective and to avoid the emergence of resistant strains of the virus. Attaining this high level of adherence is a serious concern today in the world. Because of this, provision of antiretroviral to the poor and marginalized segment of the population was the most controversial and feared act due to the number of impacts to the individual as well as to the whole of society $[8,9]$. Quality of care for clients suffering from HIV/AIDS in particular adherence to regimen and strict follow up schedules play a central role in treatment success. Therefore, the quality of care and client satisfaction strengthen the success of public health policies in enhancing access to care, especially for policies targeted at promoting access to ART [10,11]. In Ethiopia up to 2009 more than 241,236 people ever started ART and 176,644 currently on ART. ART coverage increased from $46 \%$ in 2008 to $53 \% 2009$ [12].

Correspondence to: Feleke Doyore, Faculty of Medicine and Health Science, Department of Public Health, Wachemo University, PO Box: 667, Hossana, Ethiopia, Tel: 251932685424; E-mail: feledoag@yahoo.com

Key words: client satisfaction, perception, art services, HIV/aids, Ethiopia

Received: October 23, 2016; Accepted: November 16, 2016; Published: November 19, 2016 
Doing studies on quality of care helps to identify gap between client's expectation and what has been providing for them from institution. So, better facilities, equipment, availability of drugs, staffing and training determine outcome through improving process which is the direct measure of quality [13]. Therefore, beside the expansion of the service knowing the quality of service is essential to hamper treatment failure, and build prolong productive individual after initiation of antiretroviral treatment and contribute for achievement of millennium development goal (MDG). Therefore, study is aimed to assess the quality of ART services in terms of client satisfaction at Hossana town health facilities by using quality models (Figure 1).

\section{Methods and materials}

\section{Study period and setting}

The study is conducted in ART clinics of Hossana town as of January to February, 2015. Hossana town is $230 \mathrm{~km}$ away from Addis Ababa in Southern Ethiopia. In the town currently one zonal hospital and one public health center were providing ART services. Cumulatively a total of 1,003 clients were enrolled on ART. Clients load in both health facility was assessed a week before study was conducted.

\section{Study design and populations}

Facility based cross sectional study design was used to collect data. Study populations were sampled adult clients on ART.

\section{Sample size and sampling procedure}

Sample size was determined using single population proportion formula by taking client satisfaction level $50 \%$ (assuming proportion of clients who are satisfied with quality services $),(n=[\mathrm{Za} / 2] 2 \mathrm{p}(1-\mathrm{p}) / \mathrm{d} 2)$ considering marginal error (d) of 5\%, confidence interval of $95 \%$ and $\mathrm{Z} \alpha / 2$ is the value of the standard normal distribution corresponding to a significant level of alpha $(\alpha) 0.05$, which is 1.96 . This yields a sample size of 384. Since the source population is less than 10,000, an adjustment formula (FPC), $\mathrm{nf}=\mathrm{n} / 1+\mathrm{n} / \mathrm{N}$ was used, where, $\mathrm{N}=$ Source populationSource populations were all clients receiving ART drugs in the year of 2015, $\mathrm{nf}=$ Required Sample Size, $\mathrm{n}=$ calculated sample size, Hence, the sample size were calculated at total of source population $\mathrm{N}=1003$ and $n=384$ and $n f=274$. Considering non-response rate of $10 \%$, the total sample size was 301 clients. Consecutive sampling was employed to select study participants from each facility till respective allocated sample size was filled. For qualitative, criterion related sampling technique was used to conduct four in-depth interviews with health workers and four with clients for from Hossana town health center and Nigist Elleni Mohammed Memorial General Hospital.

\section{Measurement and variables}

Outcome of this study was client satisfaction to ART services. A client satisfaction level in this study is measured continuously through Likert scale. As independent variables, the instrument comprises in part I: Socio-demographics characteristics such as age, sex, religion, marital status, educational level, income, ethnicity, residence, occupational status etc 19 items, Part II: Structure variable: minimum package/ resources requirement for provision of ART services and described comparing with guideline for implementation of ART services such as trained professionals, infrastructure, material and drugs supply, information system, time spent reach to health facility, provision of integrated services etc 12 items. Part III \& IV: Process variable and Perception related items: ways of service provision according to guideline and were measured by interviewer guide five point Likert scale questionnaire by using mean score level to describe process of service provision from clients' perspective. Perceived client-provider interaction: perceptions for service principally the received expressive content of exchanges between providers and clients. Perceived availability of resources: Clients view on availability of resources for provision of ART services (ARV drugs, opportunistic infections drugs, Trained health providers, laboratory service when needed and medical care availability during emergency services), and is assessed by five point Likert scale with five items, and explained by mean score level after computed to under one factor/component. Perceived technical competence: - Perception and knowledge of clients on ARV drugs: Clients awareness and understanding about antiretroviral treatment drugs on the effect of the time to take medication, missing dose, and consequence of missing dose or take incorrectly and is measured by four times five points Likert scale and described by mean score level and others 45 items. Each of the responses was scored as: 'strongly disagree' $=1$, 'disagree' $=2$, 'undecided $/$ not sure' $=3$, 'agree' $=4$ and 'strongly agree' $=5$. After reversing for negatively worded items, scores were summed for each respective concept. For validation of the instrument factor analysis was done during which confirmation factor loading score

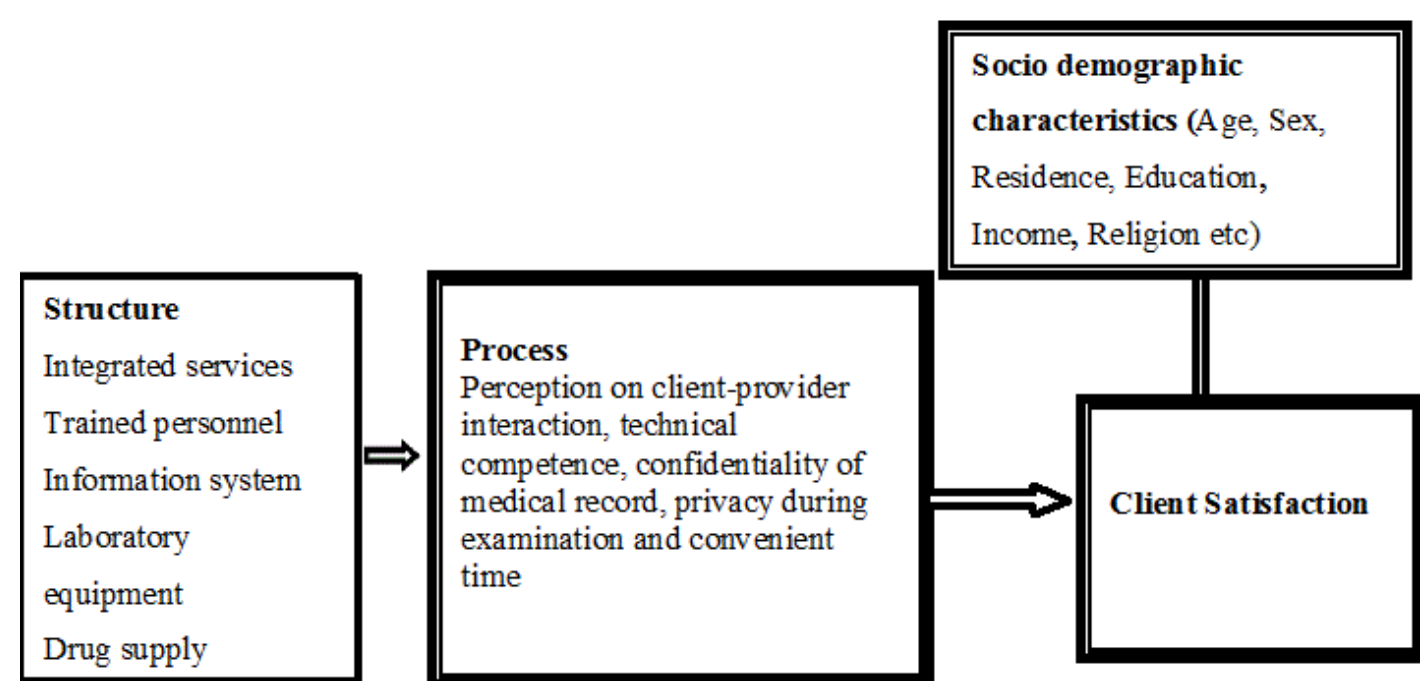

Figure 1. Conceptual frame work of Quality of ART Service adapted from Donebidean Model and Guideline for implementation of ART in Ethiopia [14-16]. 

Ethiopia

of greater than or equal to 0.4 was accepted for construct validity after using Eigen value of greater than 1 for confirming major constructs of the model. Internal consistency of items was seen separately for each construct on which items were loaded and cronbanch's alpha score of greater than or equal to 0.7 was accepted for ordinal scale items and spearman score have seen for dichotomized scale otherwise was removed. Items correlation with total correlation of scores greater than or equal to 0.3 was accepted after items internal consistency is assured otherwise were checked again and removed. For qualitative part, the qualitative data collection method was applied using in-depth interview in order to supplement the result of the quantitative data. The guideline which inquiries about the reason why they were responding or not, clients logical decisions in accepting or not accepting the pills, perceived difference of acceptors and rejecters, and delivering style with some probing questions were prepared for clients and health care providers separately. Respective responses were recorded by using tape recorder and hand written notes, and were analyzed according to their themes.

\section{Data collection instrument and procedure}

Data were collected using pre-tested structured interviewer administered questionnaire that adapted from different literatures to increase comparability of finding. There were four data collectors who are health professionals working in the ART unit and two supervisors. Training was given for data collectors and supervisors on objectives of the study, methods of data collection and ways of data collection for two days. Qualitative data were collected with in-depth interview by principal investigators from health care provider and clients. Respective responses of informants were recorded by using tape recorder and hand written notes, and were analyzed by using Atlas software.

\section{Data quality management, processing and analysis}

Questionnaires were translated to Amharic and then back translated to English to maintain its consistency. Training was given for data collectors and pretest was made on $5 \%$ of the clients in a Shurmo health center which was similar population before the actual data collection. Supervisors and principal investigators performed immediate supervision on a daily basis. Each and every completed questionnaire was checked for completeness. In qualitative study, the recorded voice was transcribed first in Amharic and translated to English to keep consistency of the original meaning.

The collected data was coded, entered a data base, cleaned and analyzed using SPSS version 16.0. Assumption checking was executed before proceeding to any kind of analysis that was done in this study. For uniform scoring of items of five point Likert scale response format; negatively worded items was reversed that higher score was given in agreement with positive statements and disagreement with negative statements. Subsequent to uniform scoring throughout the items is complete; the score of concepts identified by factor analysis was treated as factor score and thus factor score was used for further execution of prediction analysis. Descriptive statistics are used for frequency, description and data exploration. Factor analysis and reliability estimate was conducted for each components arranged to measure perception of clients on process of ART provision. Factors with reliability scores $>0.7$ of Cronbanch's alpha was taken. Perception of clients on process of ART provision was analysed as continues variable and explained by using mean score of each factor and items. Multiple linear regression analysis was used to identify the predictors of client satisfaction on ART services provision. P-value less than 0.05 were considered as cut off point for statically significant throughout the analysis.

\section{Ethical consideration}

Prior to data collection, a formal letter was obtained from Wachemo University and submitted to each health facility. All study clients were informed about the purpose of the study verbally and in written form. All clients' right to self-determination and autonomy were respected. Participation is voluntary and clients can withdraw from the study at any time.

\section{Results}

\section{Socio-demographic characteristics of the clients}

A total of three hundred one (301) clients were participated in this study producing a total response rate of $100 \%$. From the total clients, 83.1\% (250) were from Nigist Elleni Memorial General Hospital and the rest $16.90 \%$ (51) were Hossana health center. Table 1 presents sociodemographic characteristics of the clients. Accordingly, more than half, $64.80 \%$ (195/301), of the clients were females. The mean age of the clients was $31.41 \pm 6.61$ years. Regarding residence, majority, $78.40 \%$ $(236 / 301)$ of the clients came from urban areas. In terms of ethnicity, majority, $49.50 \%$ (149/301), of the clients were Hadiya followed by Kembata which accounts $16.90 \%(51 / 301)$. As far as marital status is concerned, $75.10 \%(226 / 301)$ of the clients were married. Concerning religion, $61.10 \%(184 / 301)$ clients were protestant. Of the clients, $30.60 \%(92 / 301)$ can read and write. Concerning occupational status, $27.90 \%(84 / 301)$ of the clients were employed followed by unemployed who accounts $25.20 \%$ (76/301). Majority, $60.50 \%(182 / 301)$ of the clients reported that they live with their family. Out of clients $22.60 \%$ $(68 / 301)$ were using active substance (Chat chewing, cigarette smoking and alcohol) currently and of these $57.35 \%$ (39/68) drink alcohol. Concerning disclosure of HIV Status someone else 83.40\% (251/301) of clients disclosed their HIV status for someone else. More than three fourth (237/301) were heard about availability of ART services for the first time from health providers (Table 1).

\section{Process (Provision of Services)}

Time taken and information obtained: Quality of service provision measured starting from time of entry to health facility and exit of the client as well as seeing health care provider or continual taking of prescribed drugs consistency and constantly. For this reason, clients were interviewed on time spent to reach to health facility, waiting time up to service provision, and health information provided by care providers. Table 2 presents about time spent to reach to health facility, waiting time up to service provision, and health information provided by care providers. Accordingly, 48.20\% (145/301) of clients took less than thirty minutes to arrive to health facility followed by $39.50 \%$ (119/301) clients who waited for less than 30 minutes to see health care provider. Regarding health information provided during service provision, all clients were provided health information/ education about HIV/AIDS and ARV drugs [Table 2].

\section{Perception of clients on provision of services}

The Perception of clients were assessed and perceived expectation of clients for ART services provided were measured by five point Likert scale and the mean score was used for measurement. Table 3 presents the mean score clients' perception on process quality of ART service provision. Accordingly, the average score of Perceived availability of Services was (mean \pm standard deviation) ( $38.53 \pm 15.37)$ followed by perceived technical competency was (mean \pm standard deviation) (14.60 \pm 7.01$)$. In similar speaking, in this study the overall satisfaction is 70.10 with the quality services provided in Hossana ART providing health facilities (Table 3). 
Doyore F (2016) Client satisfaction to antiretroviral treatment services and associated factors among clients attending ART clinics in Hossana Town, Southern Ethiopia

Table 1. Shows Socio-demographic characteristic of clients interviewed on client satisfaction at Hossana health facilities, Southern Ethiopia, January to February 2015 (N=301).

\begin{tabular}{|c|c|c|c|}
\hline Variable & Options & No & Percent \\
\hline \multirow[t]{2}{*}{ Facility Name } & NEMGH & 250 & 83.10 \\
\hline & $\mathrm{HHC}$ & 51 & 16.90 \\
\hline \multirow[t]{2}{*}{ Sex } & Male & 106 & 35.20 \\
\hline & Female & 195 & 64.80 \\
\hline \multirow[t]{6}{*}{ Age } & $18-24$ & 25 & 8.30 \\
\hline & $25-29$ & 79 & 26.20 \\
\hline & $30-34$ & 105 & 34.90 \\
\hline & $35-39$ & 55 & 18.30 \\
\hline & $40-44$ & 24 & 8.00 \\
\hline & $45-49$ & 13 & 4.30 \\
\hline \multirow[t]{2}{*}{ Residence } & Rural & 65 & 21.60 \\
\hline & Urban & 236 & 78.40 \\
\hline \multirow[t]{5}{*}{ Ethnicity } & Hadiya & 149 & 49.50 \\
\hline & Kembata & 51 & 16.90 \\
\hline & Amhara & 50 & 16.60 \\
\hline & Guraghe & 26 & 8.60 \\
\hline & Others* & 25 & 8.30 \\
\hline \multirow[t]{3}{*}{ Marital status } & Married & 226 & 75.10 \\
\hline & Divorced & 49 & 16.30 \\
\hline & Single & 26 & 8.60 \\
\hline \multirow[t]{4}{*}{ Religion } & Protestant & 179 & 59.5 \\
\hline & Orthodox & 104 & 34.6 \\
\hline & Muslim & 13 & 4.3 \\
\hline & Catholic & 5 & 1.7 \\
\hline \multirow[t]{5}{*}{ Educational status } & Can't read and Write & 39 & 13.00 \\
\hline & Read and Write & 92 & 30.60 \\
\hline & Primary school & 68 & 22.60 \\
\hline & Secondary school & 38 & 12.60 \\
\hline & College diploma and above & 64 & 21.30 \\
\hline \multirow[t]{5}{*}{ Occupational status } & Unemployed & 107 & 35.50 \\
\hline & Employed & 84 & 27.90 \\
\hline & Farmer & 67 & 22.30 \\
\hline & Merchants & 33 & 11.00 \\
\hline & No job & 10 & 3.30 \\
\hline \multirow[t]{4}{*}{ Monthly Income } & Median $600 \mathrm{~EB} \pm 1.08$ & & \\
\hline & Family & 182 & 60.50 \\
\hline & live alone & 106 & 35.20 \\
\hline & Parent & 13 & 4.30 \\
\hline \multirow[t]{2}{*}{ Substance use } & Yes & 68 & 22.6 \\
\hline & No & 303 & 77.4 \\
\hline \multirow[t]{3}{*}{ Substance use (type) } & Alcohol & 39 & 75.00 \\
\hline & Khat & 13 & 25.00 \\
\hline & Smoking & 24 & 46.15 \\
\hline \multirow[t]{2}{*}{ Family size } & $1-4$ & 263 & 87.38 \\
\hline & $5-8$ & 38 & 12.62 \\
\hline \multirow[t]{3}{*}{ Disclosed HIV Status someone else } & Yes & 251 & 83.40 \\
\hline & No & 37 & 12.30 \\
\hline & I don't know & 13 & 4.30 \\
\hline \multirow[t]{6}{*}{ Who know your HIV status? } & Partner & 17 & 5.60 \\
\hline & Offspring & 38 & 12.60 \\
\hline & Parent & 212 & 70.40 \\
\hline & Brother/Sister & 16 & 5.30 \\
\hline & Relative & 5 & 1.70 \\
\hline & Friend & 13 & 4.30 \\
\hline \multirow{2}{*}{$\begin{array}{l}\text { I know other health facility give } \\
\text { ART }\end{array}$} & Yes & 264 & 87.70 \\
\hline & I don't know & 37 & 12.30 \\
\hline \multirow{3}{*}{$\begin{array}{l}\text { Who told you for the first time } \\
\text { about ART services in this HF? }\end{array}$} & health professional & 237 & 78.70 \\
\hline & mass media & 52 & 17.30 \\
\hline & Relatives & 12 & 4.00 \\
\hline
\end{tabular}

"Others-Silte, Wolaita, Dawuro, Tigre, Oromo; *"- No job.
Table 2. Presents about time spent to reach to health facility, waiting time up to service provision, and health information provided by care providers ART at Hossana health facilities, Southern Ethiopia, January to February 2015 ( $\mathrm{N}=301)$.

\begin{tabular}{|c|c|c|c|c|}
\hline Variables & Options & Frequency & Percent & Remark \\
\hline \multirow{4}{*}{$\begin{array}{l}\text { How long did it take to you to } \\
\text { arrive at this Health facility? }\end{array}$} & $<30 \min$ & 145 & 48.20 & \\
\hline & $30 \min -1: 00$ & 119 & 39.50 & \\
\hline & 1:00-2:00 & 13 & 4.30 & \\
\hline & $>2: 00$ & 24 & 8.00 & \\
\hline \multirow{4}{*}{$\begin{array}{l}\text { How long did you wait before } \\
\text { seeing health provider? }\end{array}$} & No wait & 238 & 79.00 & \\
\hline & $<30 \min$ & 39 & 13.00 & \\
\hline & $30 \min -1: 00$ & 0 & 0.00 & \\
\hline & 1:00 and above & 24 & 8.00 & \\
\hline \multicolumn{2}{|c|}{$\begin{array}{l}\text { Information given to clients about HIV/AIDS and ARV } \\
\text { drugs during appointment date }\end{array}$} & 301 & 100.00 & \\
\hline \multicolumn{2}{|l|}{ AIDS has no cure } & 301 & 100.00 & \\
\hline \multicolumn{2}{|l|}{ Benefit of ART drugs } & 289 & 96.00 & \\
\hline \multicolumn{2}{|l|}{ Side effect of ART } & 289 & 96.00 & \\
\hline \multicolumn{2}{|l|}{ Treatment is life long } & 288 & 95.70 & \\
\hline \multicolumn{2}{|l|}{ Adherence to treatment is crucial } & 291 & 96.70 & \\
\hline \multicolumn{2}{|c|}{ Practicing safe sex while on treatment is crucial } & 283 & 95.3 & \\
\hline
\end{tabular}

Table 3. Presents perception of clients on process service provision by their scale range of the clients in Hossana health facilities, Southern Ethiopia, January- February 2015 (N=301).

\begin{tabular}{|c|c|c|c|}
\hline Clients Perception & Scale range & Scale Mean & SD \\
\hline Perceived availability of Services & $11-55$ & 38.53 & 15.37 \\
\hline Perceived technical competence of health providers & $4-20$ & 14.60 & 7.01 \\
\hline Perceived client provider interaction & $7-35$ & 27.37 & 12.49 \\
\hline Perception \& knowledge of clients on ARV drugs & $6-30$ & 19.65 & 8.79 \\
\hline Perceived privacy during examination & $1-5$ & 4.02 & 1.06 \\
\hline Perceived confidentiality of medical record & $1-5$ & 4.03 & 1.06 \\
\hline $\begin{array}{l}\text { Perceived convenient of physical setting of ART } \\
\text { services }\end{array}$ & $1-5$ & 3.38 & 1.33 \\
\hline Perceived convenient of opening hours & $1-5$ & 4.18 & 0.94 \\
\hline Overall Satisfaction of Client on ART Services & $5-25$ & 17.27 & 3.22 \\
\hline
\end{tabular}

\section{Predictors of quality services in terms of client satisfaction}

Looking into the effect of socio-demographic factors, perceptions of clients, time spent to reach health facility, information given to clients about ARV drugs during appointment date, and considering as process and outcome of service provision in Donebidean model, adjustment was made to see association of variables by far the description of each concept considered as variables for prediction of client satisfaction in the model.

Regarding the socio-demographic variables as covariates (Table 1) educational status, clients who disclosed to their parents had significant crude and adjusted effect on client satisfaction. Accordingly, those clients who completed primary school as compared to those who can't read and write had higher odds of satisfaction for ART with odds ratio $[\beta(95 \% \mathrm{CI})=2.41(3.97-9.74)]$. Similarly, those clients who are disclosed to their HIV status to their parents as compared to those are not had higher odds of satisfaction for ART with odds ratio $[\beta(95 \% \mathrm{CI})=4.33$ (2.39-8.18)] those clients who are more satisfied than disclosed any. In the same speaking, regarding the perceptions of clients, for instance perceived availability of the services for HIV/AIDS/ ART service provision had a statistical significant effect on satisfaction with beta coefficients $[\beta(95 \% \mathrm{CI})=1.79(1.07-3.01)$, perceived patient provider interaction $[\beta(95 \% \mathrm{CI})=1.76(1.07-2.88)$, perceived confidentiality of medical record $[\beta(95 \% \mathrm{CI})=1.26(0.67-0.98)$, and perceived privacy during examination $[\beta(95 \% \mathrm{CI})=1.16(1.03-1.31)]($ Table 4$)$. 
Doyore F (2016) Client satisfaction to antiretroviral treatment services and associated factors among clients attending ART clinics in Hossana Town, Southern Ethiopia

Table 4. Multiple linear regression analysis ((Unstandardized $\beta(95 \% \mathrm{CI})$ and Standardized $\beta(95 \% \mathrm{CI})$ ) for final model prediction for client satisfaction among clients of hosanna health facilities, Southern Ethiopia, January to February 2015.

\begin{tabular}{|c|c|c|c|c|c|}
\hline Variables of Equations & Options & No & $\%$ & Unstandardized $\beta(95 \% \mathrm{CI})$ & Standardized $\beta(95 \% C I)$ \\
\hline Perceived availability of the services & Mean \pm standard deviation & 38.53 & 15.37 & $2.34(1.28-4.28)$ & $1.79(1.07-3.01)^{*}$ \\
\hline Perceived patient provider interaction & Mean \pm standard deviation & $7-35$ & 27.37 & $3.69(1.17-11.66)$ & $1.76(1.07-2.88)^{*}$ \\
\hline Perceived privacy during examination & Mean \pm standard deviation & 4.01 & 1.03 & $1.30(1.21-1.40)^{*}$ & $1.16(1.03-1.31)^{*}$ \\
\hline Perceived confidentiality of medical record & Mean \pm standard deviation & 3.99 & 1.02 & $1.62(0.94-2.79)$ & $1.26(0.67-0.98)^{*}$ \\
\hline \multirow[t]{5}{*}{ Educational status } & Can't read \& Write & 39 & 13.00 & 1 & 1 \\
\hline & Read and Write & 92 & 30.60 & $1.07(0.49-2.31)$ & $1.04(0.31-3.53)$ \\
\hline & Primary school & 68 & 22.60 & $2.91(1.19-7.15)^{*}$ & $2.41(3.97-9.74)^{*}$ \\
\hline & Secondary school & 38 & 12.60 & $1.53(0.59-3.98)$ & $1.51(0.95,3.18)$ \\
\hline & College diploma \& above & 64 & 21.30 & $1.60(0.69-3.72)$ & $1.51(0.95,3.18)$ \\
\hline \multirow[t]{6}{*}{ Who disclosed to } & Partner & 17 & 5.60 & 1 & 1 \\
\hline & Offspring & 38 & 12.60 & $3.84(0.83-17.71)$ & $2.64(0.35-20.18)$ \\
\hline & Parent & 212 & 70.40 & $5.16(1.34-19.78)$ & $4.33(2.39-8.18)^{*}$ \\
\hline & Brother/Sister & 16 & 5.30 & $4.05(1.28-12.89)$ & $2.63(0.13-51.39)$ \\
\hline & Relative & 5 & 1.70 & $2.05(0.46-9.14)$ & $1.26(0.17-9.61)$ \\
\hline & Friend & 13 & 4.30 & $6.40(0.55-74.89)$ & $6.3(0.92-50.41)$ \\
\hline
\end{tabular}

"statistically significant at $\mathrm{p}$ value $<0.05 ; 1$ is Odds ratio for reference category.

\section{Discussion}

This study has shown that the overall client satisfaction in ART service was $70.10 \%$. The study is lower than the study conducted Tigray slightly [17]. However, as discussed above, the current literature is not in total agreement about these predictors, so perhaps this lends itself to the idea that such determinants might be more locally than generally associated with client satisfaction.

In this study, perception of client on the availability of the services had positive association with client satisfaction. Health workers from the hospital and HC said that almost the CDC recommendation for ART has been fulfilled in terms of human resources, material resources and equipment's. For frankly speaking, lack of waiting area is our problem in both health facilities, this might have effect on extent satisfaction of client's on service provided; I hope this will be solved through discussion. As to me being ART by itself may make them not to be satisfied rather the services are good". This study is in line with the study conducted in India and Ethiopia [14-20].

In this study, perceived client provider interaction had positive association with client satisfaction. This study is in line with the studies conducted in abroad and Ethiopia as well as the very nature of Donebidean model [14-21]. Similar to this concept in qualitative part, all clients explained that $A R V$ drugs are available during their appointment session. One ART provider of hospital said, even if, sometimes we encountered shortage of $A R V$ drug, the clients were never sent without $A R V$ drugs and we give from other nearby health facility. For frankly speaking, sometimes, there is encountered shortage of prescribed drugs for opportunity infection, and our clients were sometimes obliged to buy outside of hospital or health center. Resource wise, human power, examination and counseling room and pharmacy there in hospital but this may a bit problem in health. In Hossana health center, human resources wise I am only one provider was assigned for provision of ART services. One health officer who is adherence supporter here in our health center and she also replaces me since she took every training that I have taken. Though I am very happy in this service provision since I am helping several individuals, I was normalized due to shortage of human resources even I am focal for more than five teams. You know we are providing this services for client with this narrow room whatever we are committed work overload and restless decrease our service quality of care which in turn decreases client satisfaction".
In this study, perceived privacy during examination and confidentiality of medical record had positive association with client satisfaction. Almost all the participants of in-depth interview were agreed that things are kept secret and they believe as their information was confidential. And also health care providers reported as the issue of confidentiality is $100 \%$. However, privacy issue is might not be sometimes $100 \%$ because of narrowness of the class and attachment of the room to the other health care services. This study is in line with the studies conducted in abroad and Ethiopia as well as the very nature of Donebidean model [14-16,21]. In this study, those clients who completed primary school had positive significant association with client satisfaction as compared to with those who can't read and write. This is also supported by qualitative part, one of the health workers who is working in ART said that "mostly educated peoples and whose social status are high will come for the treatment as compared to those lower in education and economic status". This study is similar to the study conducted in abroad and most of the Ethiopian countries [19-21].

This study found that disclosing the status of HIV to their parents had significant association to client satisfaction as compared to who disclosed any. One client who is taking ART for not less than six months said that "we are frank to talk with our family whatever the situation will be. I am not ashamed of taking ART drugs since my family supports even reminds me to take the drug. By the way, the existence ART by itself makes me to be satisfied". This potential reason may be those families who modernize themselves and who care for their families teach them in each corner of health issues; i.e. sense of modernization [22].

\section{Strength of the study}

The current study used tested model for evaluation as conceptual frame work. Qualitative and quantitative data are triangulated. Limitation of the study: in case client satisfaction, the researcher used five point Likert scale, this may not precisely told us to say so.

\section{Conclusion}

Despite of the fact that higher numbers of clients were satisfied in the services provided, significantly intolerable numbers were not satisfied in the service provided. Our study found that some sociodemographic characteristics and perceptions about services provision were associated with overall satisfaction, though many were not. Although previous work had shown most of the facility related factors 
were associated with satisfaction, this study did not support that finding. Also, neither waiting time nor travel-time was related to the overall satisfaction. However, as discussed above, the current literature is not in total agreement about these predictors, so perhaps this lends itself to the idea that such determinants might be more locally than generally associated with client satisfaction. Even though majority of structural requirement for provision of ART service according to guideline were available, there were different gaps exist within both health facilities. Shortages and tied examination and counseling room, absence of nutritional support, shortage of some OI drugs, adherence nurses being more than one focal, Otoscope clinical chemistry auto analyses and reagent hematology auto analyzer in Hossana health Center as guideline.

Generally, the independent predictors of the quality of services in terms client satisfaction are educational status, disclosure status to their parents and perception of respondents in service provision based constructs of Donebidean model had a significant effect on client satisfaction to ARV drugs.

\section{Recommendations}

To zonal health department, health offices, health facilities, HIV/AIDS prevention and control offices, researcher and any organizations working in the area of ART should follow the following recommendations.

- Zonal health department should formulate and adopt new innovations and important evaluation theories and approaches that may help the existing health policy in general and ART services evaluation trend in particular in order to promote positive behavior. Besides, the zone should strengthen shared vision with community and stake holders to have strategic communication.

- $\quad$ Special attention should be given for ART service during integration supervision of health facilities undertaken through clinical mentorship and developing IEC/BCC materials for awareness creation.

- $\quad$ Since the existence of the services is the best predictor of satisfaction. Availability resources for provision of ART services (OI, drugs, ARV drugs, trained human power, etc) should continuously avail for clients during their appointment.

- Refreshment training should be given for those who have been engaged in provision of the ART service.

- Zonal health department directly go to the grass-root level and assess any inconveniences and gap identified by the study among the group.

- Researchers should do further research on determinants of quality of ART services using strong methods.

\section{Competing interests}

The authors declared that have no competing interests.

\section{Authors' contributions}

Feleke Doyore and Beminet Moges wrote the proposal, participated in data collection, analyzed the data and drafted the paper. Research committee approved the proposal with some revisions, supervised in data collection and analysis, commented on the analysis and improved the first draft. Both authors revised subsequent drafts of the paper. Feleke Doyore prepared this manuscript.

\section{Acknowledgment}

We are very grateful to the clients who were willing to be interviewed. Although they were made to understand that they would not benefit personally from participating in this study, they were convinced that their views were valuable in the drive towards making health care satisfactory to clients attending ART clinic. We also thank our research data collectors who collected the data. The baseline study as a whole could not have been conducted without the permission and support of the health institutions authorities. We are grateful to them. Above all, we are grateful to the Wachemo University for the financial support through the research funding that enabled us to do the study.

\section{References}

1. Weiser SD, Heisler M, Leiter K, Percy-de Korte F, Tlou S, et al. (2006) Routine HIV testing in Botswana: a population-based study on attitudes, practices, and human rights concerns. PLoS Med 3: e261.[Crossref]

2. UNAIDS (2007) Guidance on Provider-Initiated Testing and Counselling in Health Facilities. HIV/AIDS Programme, WHO.

3. UNAIDS (2007) Report on Global HIV/AIDS statistics. WHO

4. HAPCO F (2010) Report on Progress towards Implementation of the UN Declaration of Commitment on HIV/AIDS. Federal Democratic Republic of Ethiopia.

5. Mocroft A, Vella S, Benfield TL, Chiesi A, Miller V, et al. (1998) Changing patterns of mortality across Europe in clients infected with HIV-1. EuroSIDA Study Group. Lancet 28: 1725-1730.

6. UNAIDS (2009) Report on global AIDS epidemic. WHO

7. Gill CJ, Hamer DH, Simon JL, Thea DM, Sabin LL (2005) No room for complacency about adherence to antiretroviral therapy in sub-Saharan Africa. AIDS 19: 1243-1249. [Crossref]

8. Paterson DL, Swindells S, Mohr J, Brester M, Vergis EN, et al. (2000) Adherence to protease inhibitor therapy and outcomes in patients with HIV infection. Ann Intern Med 133: 21-30.[Crossref]

9. Anti-retrovirus therapy program for HIV- infected clients in Ethiopia (2002) Protoco prepared by Ethiopian Health and Nutrition research institute, Black Lion Hospital, Police Hospital, and Armed Force General Hospital.

10. Dixon S, McDonald S, Roberts J (2002) The impact of HIV and AIDS on Africa's economic development. BMJ 324: 232-234.[Crossref]

11. Mesfin MM, Newell JN, Walley JD, Gessessew A, Tesfaye T, et al. (2009) Quality of tuberculosis care and its association with patient adherence to treatment in eight Ethiopian districts. Health Policy Plan 24: 457-466.[Crossref]

12. FHAPCO (2009) ART Scale-up in Ethiopia, Success and Challenges.M\&E Directorate.

13. USAID (2010) ART Client Uptake Status Update. MSH/SPS.

14. Donabedian A (1980) The Definition of Quality and Approaches to Its Assessment Ann Arbor, MI: Health Administration Press.

15. Donabedian A (1966) Evaluating the quality of medical care. Milbank Mem Fund $Q$ 44: Suppl:166-206.[Crossref]

16. Donabedian A (1980)The Definition of Quality and Approaches to Its Assessment. Vol 1. Explorations in Quality Assessment and Monitoring. AHRQ.

17. Tessema SB, Adane MM (2015) Assessment of antiretroviral treatment (ART) care service provision in Tigray Region health centers, North Ethiopia.BMC Health Serv Res 15: 368.

18. Kane RL, Maciejewski M, Finch M (1997) The relationship of patient satisfaction with care and clinical outcomes. Med Care 35: 714-730.[Crossref]

19. Avina S, Bachani D, Sebastain M, Sogarwal R,Battala M (2010) Factors affecting enrolment of PLWHIV into ART services in india. Naco population Council.

20. Sogarwal R1, Bachani D (2009) Assessment of ART centres in India: client perspectives. J Indian Med Assoc 107: 276-280.[Crossref]

21. Asmare M (2014) Level of ART Adherence and Associated Factors among HIV Sero- 
Doyore F (2016) Client satisfaction to antiretroviral treatment services and associated factors among clients attending ART clinics in Hossana Town, Southern Ethiopia

Positive Adult on Highly Active Antiretroviral Therapy in Debre Markos Referral Hospital, Northwest Ethiopia. J Antivir Antiretrovir 6: 120-126.
22. Weiser SD, Heisler M, Leiter K, Percy-de Korte F, Tlou S, et al. (2006) Routine HIV testing in Botswana: a population-based study on attitudes, practices, and human rights concerns. PLoS Med 3: e261.[Crossref]

Copyright: (O2016 Doyore F. This is an open-access article distributed under the terms of the Creative Commons Attribution License, which permits unrestricted use, distribution, and reproduction in any medium, provided the original author and source are credited. 